\title{
Mechanical and metallurgical properties of DP 1000 steel square butt welded joints with GMAW
}

\author{
Ianto Cáceres Leite Rocha ${ }^{1 *}$; Ivan Guerra Machado ${ }^{1}$; Cíntia Cristiane Petry Mazzaferro ${ }^{2}$ \\ ${ }^{1}$ Federal University of Rio Grande do Sul, PPGE3M, Welding \& Related Techniques Laboratory \\ ${ }^{2}$ Federal University of Rio Grande do Sul, PROMEC, Welding \& Related Techniques Laboratory \\ *Corresponding author E-mail: iantorocha@gmail.com
}

Copyright () 2015 Ianto Cáceres Leite Rocha et al. This is an open access article distributed under the Creative Commons Attribution License, which permits unrestricted use, distribution, and reproduction in any medium, provided the original work is properly cited.

\begin{abstract}
In this work, Gas Metal Arc Welding (GMAW) was used to study the influence of heat input (i.e. cooling rate) on mechanical/metallurgical properties of square butt welded joints of DP 1000 sheets. The influence of filler metals of different strengths on the mechanical properties of joints was also tested. A significant decrease in hardness was observed in the Heat Affected Zone (HAZ) due to martensite tempering, in regions where peak temperature was close to isotherm $\mathrm{AC} 1$ (calculated in $735^{\circ} \mathrm{C}$ for these steel); coincidently, fracture in every tensile test occurred in regions where martensite was tempered, even when a wire of less strength was used. It was noticed that the decrease in ultimate tensile and yield strength of base metal was inherent to welding. When minimum heat input was used, deterioration in mechanical properties was less pronounced, once degree of HAZ softening was smaller. Elongation of joints increased with increasing heat input.
\end{abstract}

Keywords: Welding; Dual Phase (DP 1000) Steel; Microstructures; Softening; Mechanical Properties.

\section{Introduction}

There is worldwide need to develop structures that are lightweight and strong, for various applications. For example, automakers constantly seek to develop vehicles that maximize fuel efficiency and minimize pollutants, without compromising on vehicle safety, and this hinges on the development of lightweight components [1]. In Brazil, the rules on allowable weight of truck parts have become very strict since 2009 , driven by the need to prevent deterioration of national highways and roads that are the main routes for goods transportation throughout the country.

Dual Phase (DP) steels, a class of Advanced High Strength Steels (AHSS), are strong contenders for fabrication of lightweight automobile parts, which can meet the demands of weight, ductility and strength. These steels have ultimate tensile strength that ranges from $500 \mathrm{MPa}$ to $1200 \mathrm{MPa}$, depending on the DP grade. They also have other attractive features such as good conformability and weldability, besides high work hardening rates and bake hardening capability. [1], [2].

The classification of dual phase steels is based on their biphasic microstructure. DP steels are typically composed of dispersed islands of martensite in a ferritic matrix. The two phases behave like a composite material; the soft ferrite grants good conformability, while martensite improves the strength of the material [2]. Askoy and Esin [3] have linked the mechanical properties of DP steels to the following key microstructural factors: (1) martensite morphology; (2) volume fractions of each phase; (3) ferritic grain size; (4) uniformity of dispersion of the martensitic grains in the ferrite matrix and; (5) spacing between the martensitic grains.

As with many AHSS, almost any welding process can be employed with DP steels, although low-hydrogen consumables are preferred [4]. Industrially the most frequently employed processes are gas metal arc welding (GMAW), resistance spot welding and laser welding. One of the main problems in the welding of DP steels is Heat Affected Zone (HAZ) softening due to non-isothermal tempering of martensite, which occasionally promotes fracture in this region [5]. This phenomenon is also responsible for reduced yield and tensile strength of joints in this material [6]. 
HAZ softening is related to cooling rate (heat input), prestrain, DP martensite content and chemical composition, especially $\mathrm{Mn}, \mathrm{Cr}$ and Mo [5-8]. The present work studies the effect of different heat inputs (cooling rates) on HAZ softening and its effects on mechanical properties of DP welded joints with GMAW. The effect of two filler metals - of different strength - on mechanical properties of these joints is also analyzed.

\section{Material and methods}

\subsection{Base metal}

Commercial, $1.8 \mathrm{~mm}$ thick DP 1000 sheets were used as base metal for the experiments. Table 1(a, b) shows the mechanical properties and chemical composition of this steel sample; as can be seen, the ultimate tensile strength is over $1000 \mathrm{MPa}$. The low contents of carbon, phosphorous and sulfur promise good weldability for this steel and it can be seen that the amount of $\mathrm{Nb}$ suggests that it was the main alloying element used for grain refinement, probably to inhibit grain recrystallization as described by Granbom [9].

Table 1: (A) Base Metal Mechanical Properties

\begin{tabular}{llll}
\hline Yield Strength $(\mathrm{MPa})$ & Tensile Strength $(\mathrm{MPa})$ & Elongation $(\%)$ & Hardness $(\mathrm{HV} 0.5)$ \\
\hline 802 & 1099 & 5 & 325 \\
\hline
\end{tabular}

Table 1: (B) Base Metal Chemical Composition

\begin{tabular}{llllllll}
\hline \multicolumn{7}{c}{ Chemical Composition (mass \%) } \\
\hline $\mathrm{C}$ & $\mathrm{Si}$ & $\mathrm{Mn}$ & $\mathrm{P}$ & $\mathrm{S}$ & $\mathrm{Cr}$ & $\mathrm{Mo}$ & $\mathrm{Ni}$ \\
\hline 0.123 & 0.484 & 1.44 & 0.0102 & 0.0016 & 0.0122 & $<0.005$ & 0.0275 \\
\hline $\mathrm{Al}$ & $\mathrm{Co}$ & $\mathrm{Cu}$ & $\mathrm{Nb}$ & $\mathrm{Ti}$ & $\mathrm{V}$ & $\mathrm{W}$ & $\mathrm{B}$ \\
\hline 0.0433 & 0.0161 & 0.0105 & 0.0156 & 0.0045 & 0.007 & $<0.010$ & 0.0002 \\
\hline
\end{tabular}

The microstructural analyses of the base metal and the joints were done by light microscopy using $2 \%$ Nital as etchant. Immersing times were 4-5 s. Figure 1(a) shows the base metal cross section, which is composed of ferrite (light) and martensite (dark) phases. It can be seen that the grains are elongated as a consequence of thermomechanical processing. Figure 1(b) shows the longitudinal section, where regions of martensite (dark) bands are seen. These probably occurred due to manganese segregation [10]. Volume fraction of phases was measured following ASTM 562 [11], and the composition was found to be $51 \%$ of ferrite and $49 \%$ martensite (error of $\pm 4 \%$ for both phases).

(A)

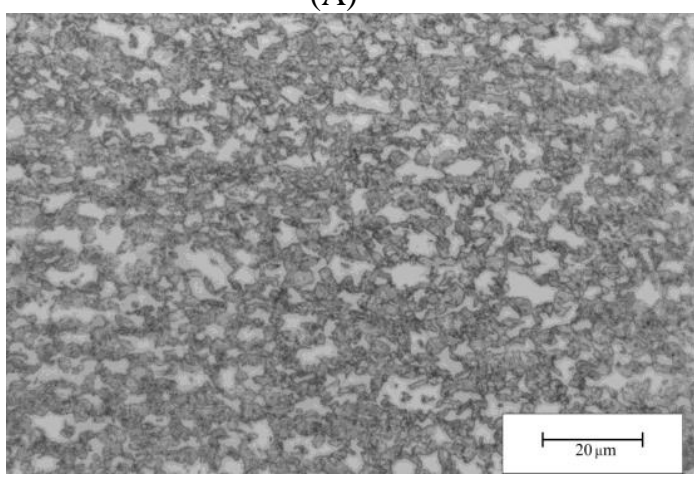

(B)

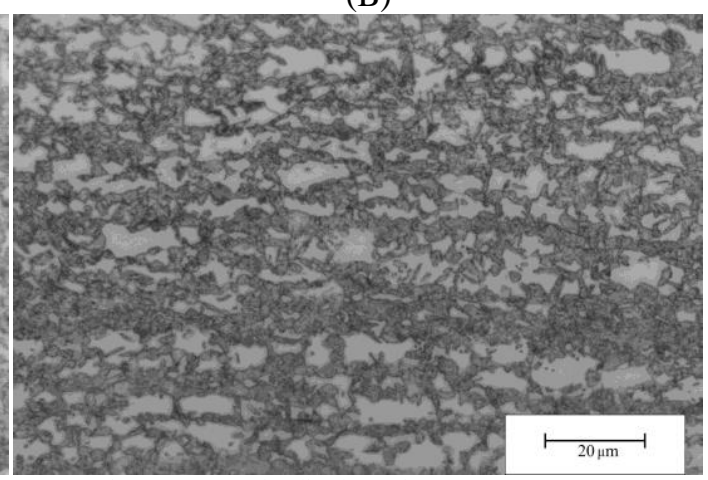

Fig. 1: Micrographs of DP 1000. (A) Cross Section; (B) Longitudinal Section

\subsection{Experimental procedure}

Coupons measuring $90 \times 170 \mathrm{~mm}^{2}$ of base metal were welded by synergic GMAW using a mixture of Ar with $25 \%$ $\mathrm{CO} 2$ as shielding gas. Weld beads (length $170 \mathrm{~mm}$ ) were made perpendicular to base metal rolling direction, with four different heat inputs, full joint penetration, and one weld with the lowest heat input as possible.

The four heat inputs were attained through welding speed, that is, both current and voltage were the same for all experiments. Welds were made using a robot with a synergic power source. The base metal coupons were attached into a solid block of steel on top of a backing made of copper with root size of $0.5 \mathrm{~mm}$. They were welded in flat position, $20 \mathrm{~mm}$ stick out, and 15 1/min gas flow rate.

The solid wire filler metals were AWS ER80S-G and AWS ER120S-G, both with $1.2 \mathrm{~mm}$ gauge, although the latter was only used in order to verify if a stronger filler would effectively affect the final mechanical properties of the joint. It 
did not, as will be seen below, and so most results here are only for AWS ER80S-G. The mechanical properties of both filler metals are shown in Table 2. Notice that the values of yield and tensile strength are minimum.

Table 2: Filler Metal Mechanical Properties, According To Manufacturer.

\begin{tabular}{llll}
\hline Filler Metal & Yield Strength $(\mathrm{MPa})$ & Tensile Strength $(\mathrm{MPa})$ & Elongation $(\%)$ \\
\hline AWS ER80S-G & 540 & 625 & 26 \\
\hline AWS ER120S-G & 810 & 900 & 18 \\
\hline
\end{tabular}

For accurate measurement of current, voltage and temperature during welding, high speed data acquisition systems were used. Table 3 shows the welding conditions (averages of current and voltage) for weldments made with AWS ER80SG. Four weldments with AWS ER120S-G were made with the same welding conditions.

Table 3: Welding Conditions

\begin{tabular}{llllll}
\hline Weldment & $\begin{array}{l}\text { Average Current } \\
(\mathrm{A})\end{array}$ & $\begin{array}{l}\text { Average Voltage } \\
(\mathrm{V})\end{array}$ & $\begin{array}{l}\text { Welding Speed } \\
(\mathrm{mm} / \mathrm{s})\end{array}$ & $\begin{array}{l}\text { Average Heat Input } \\
(\mathrm{kJ} / \mathrm{mm})\end{array}$ & $\begin{array}{l}\Delta \mathrm{t} / 5 \\
(\mathrm{~s})\end{array}$ \\
\hline W1 & 133.5 & 20.7 & 13.0 & 0.2 & 4.5 \\
W2 & 131.6 & 20.6 & 5.0 & 0.5 & 5.6 \\
W3 & 133.1 & 20.6 & 3.8 & 0.7 & 8.2 \\
W4 & 131.7 & 20.6 & 2.5 & 1.1 & 11.7 \\
\hline
\end{tabular}

Thermal cycles were obtained using five type $\mathrm{K}$ thermocouples, which were always positioned at the same relative places to the weld beads. However the interval of time between 800 and $500 \mathrm{oC}$ during cooling $(\Delta \mathrm{t} / 5 / 5)$, which is a common parameter to evaluate cooling rates in welding of steels, could not be calculated using the thermal cycles obtained by type K thermocouples; it could only be done by type $\mathrm{S}$ ones. So to calculate $\Delta \mathrm{t} 8 / 5$, each heat input had one weld metal harpooned by a type $\mathrm{S}$ thermocouple. The results are shown in table 3 .

The joints were cross-sectioned for metallographic analysis, microhardness profiles and uniaxial tensile testing. The Vickers hardness profiles were made following the ASTM E384 [12] standard, with $500 \mathrm{~g}$ load, dwell time of $10 \mathrm{~s}$ and $0.3 \mathrm{~mm}$ between indentations. The ASTM E8/E8M [13] standard was used for tensile testing and to dimension the subsize specimen. All micro/macrographs were made with the same etching technique employed for the base metal.

\section{Results and discussions}

\subsection{Microhardness and geometry of joints}

The weld metal cross section areas of the joints were measured, with average results plotted as a function of heat input in Figure 2. The nonlinear behavior is apparently connected to the fact that heat input efficiency varies with welding speed. In general, faster welding speeds imply higher efficiency, and perhaps this justifies the fall of slope from the smaller $(0.2 \mathrm{~kJ} / \mathrm{mm})$ to the higher $(1.1 \mathrm{~kJ} / \mathrm{mm})$ heat input.

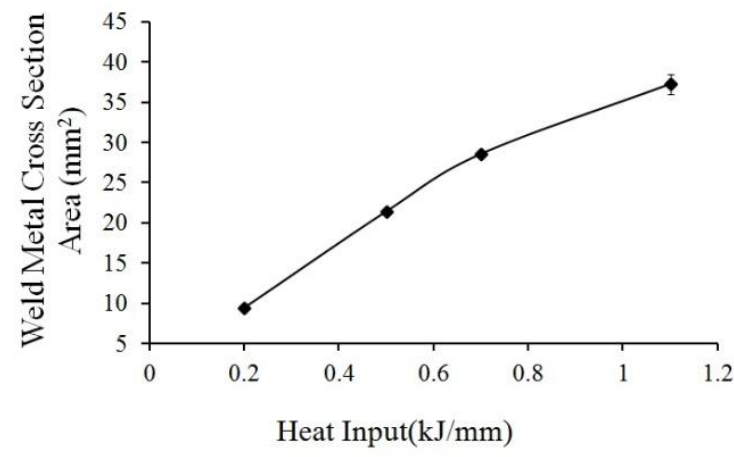

Fig. 2: Welded Joints Average Weld Metal Cross Section Area as a Function of Heat Input.

Transverse hardness profiles of all experiments were made at half height of the base metal cross section, in order to understand the evolution of microstructures developed along the welded joints. A common hardness profile to all welded joints can be seen in Figure 3, exemplified by experiment W3 with its macrograph. Apart from the unaltered base metal and weld metal, four different regions found in the heat affected zone (HAZ) are highlighted, i. e., tempered base metal (TBM), subcritical region (SCR), intercritical region (ICR) and grain coarsening region (GCR). An analysis of the HAZ shows that the highest values of hardness are developed in the grain coarsening region and that the smallest occur in the subcritical region. Notice that the reinforcement is exaggerated due to the high heat input. 


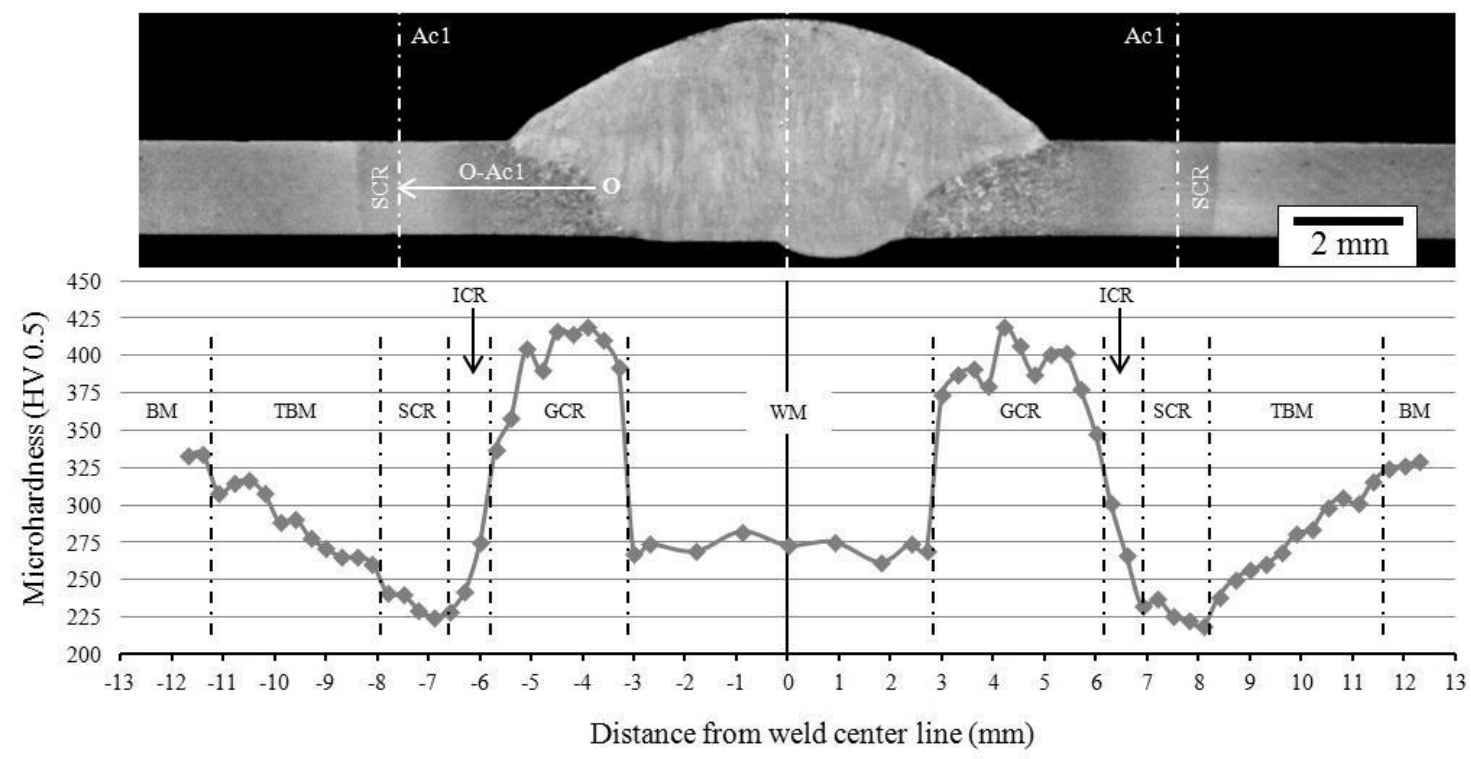

Fig. 3: Macrograph of W3 $(0.7 \mathrm{~kJ} / \mathrm{mm})$ and Its Hardness Profile. BM: Base Metal; TBM: Tempered Base Metal;

Figure 3 also shows vector O-Ac1 that was the standard measure created to assess the extent of the HAZ in the experiments. This vector whose origin $\mathrm{O}$ is located at half height of the base metal, measures the distance from the edge of the weld metal $(\mathrm{O})$ to the $\mathrm{AC1}$ isotherm. Using the chemical composition of DP 1000, the value of AC1 was calculated using Trzaska's equation [14] (1), resulting in $735 \pm 8{ }^{\circ} \mathrm{C}$. In the macrographs, the $\mathrm{AC} 1$ isotherm corresponded to a very prominent line, which overlapped the boundary of two distinct regions: the subcritical region and intercritical region.

$\mathrm{AC} 1=739,3-22,8(\mathrm{C})-6,8(\mathrm{Mn})+18,2(\mathrm{Si})+11,7(\mathrm{Cr})-15(\mathrm{Ni})-6,4(\mathrm{Mo})-5(\mathrm{~V})+28(\mathrm{Cu})$

Through measurements made using type $\mathrm{K}$ thermocouples, it seems really probable that the line demarcating this boundary corresponds to AC1. This is shown in the macrograph of Figure 4, where thermocouples are positioned according to their distances from the weld bead toe. As can be seen, the thermocouples recorded peak temperatures above $735^{\circ} \mathrm{C}$; furthermore, their associated coordinates overlapped the intercritical region of the correspondent macrograph. Notice that the thermocouples where positioned transversely at a same distance from the weld bead, but they were separated longitudinally.

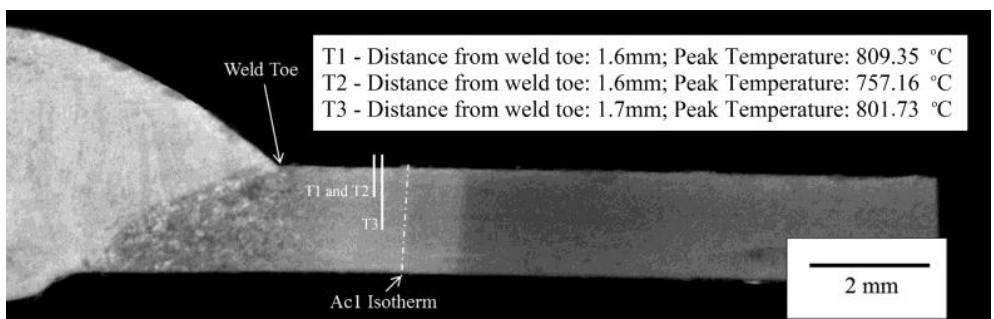

Fig. 4: Registered Peak Temperatures by the Type K Thermocouples and Their Respective Positions Regarding the Weld Toe.

Figures 5(a,b) shows minimal microhardness of HAZ and average microhardness of both weld metal and grain coarsening region, as a function of heat input. Figure 5(a) is for weldments with filler metal AWS ER80S-G and Figure 5(b) is for those with AWS ER120S-G. It can be seen that for the same heat input, there is no difference between them for average microhardness of grain coarsening region and minimal HAZ microhardness, although weldments with stronger filler metals always had weld metals with higher microhardness, as expected.

Figures $5(\mathrm{a}, \mathrm{b})$ confirms that grain coarsening region has extremely high values of microhardness compared to the average values in the case of the weld metal. It is also seen that this region had the highest values of microhardness for all weldments, even when the stronger filler metal was used. Comparing the minimum measured microhardness in HAZ with the weld metals values, it is clear that the minimum values of hardness for any joint were always located in HAZ. Weld metals of both wires showed the same response to heat input variation; there is a significant drop in average microhardness between the smallest heat input and higher heat inputs, due to microstructure alteration. Although Figures $5(\mathrm{a}, \mathrm{b})$ show variations in microhardness in regions of HAZ, they were not enough to point significant microstructure variations in HAZ between weldments.

Figure 6 shows the results of O-AC1 measurements. As mentioned previously, the size of the HAZ increases with heat input, for $\mathrm{O}-\mathrm{AC} 1$ size almost doubled from the lowest to the highest heat input. The contrast in O-AC1 extension among heat inputs goes along with the variation of welding speed. When high welding speeds are used, the isotherms 
tend to get closer to each other [15], narrowing the HAZ. When lower speeds are used, the opposite behavior is expected, expanding the HAZ.

(A)

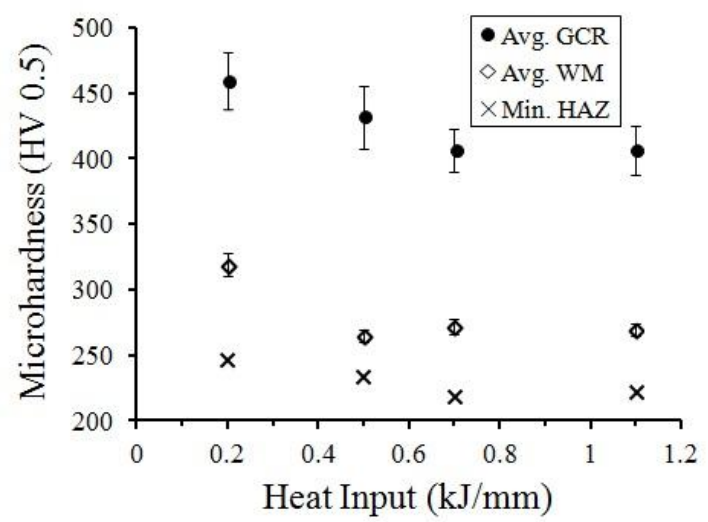

(B)

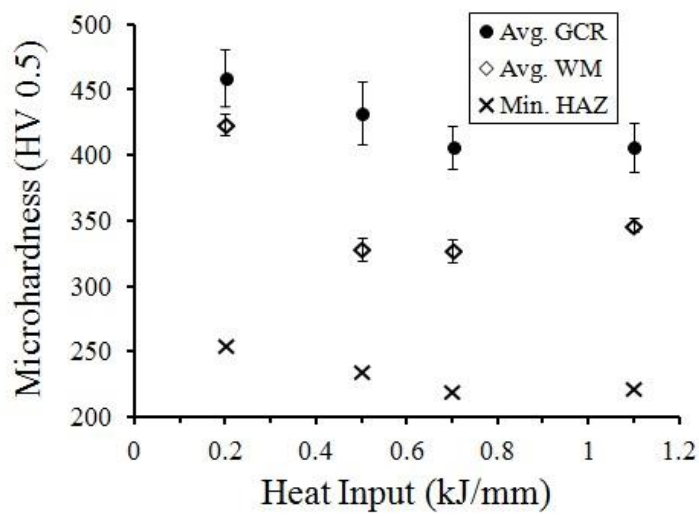

Fig. 5: Minimum Microhardness In HAZ and Average Microhardness Both Weld Metal and Grain Coarsening Region as Function of Heat Input, (A) Weldments with AWS ER80S-G and (B) with AWS ER120S-G.

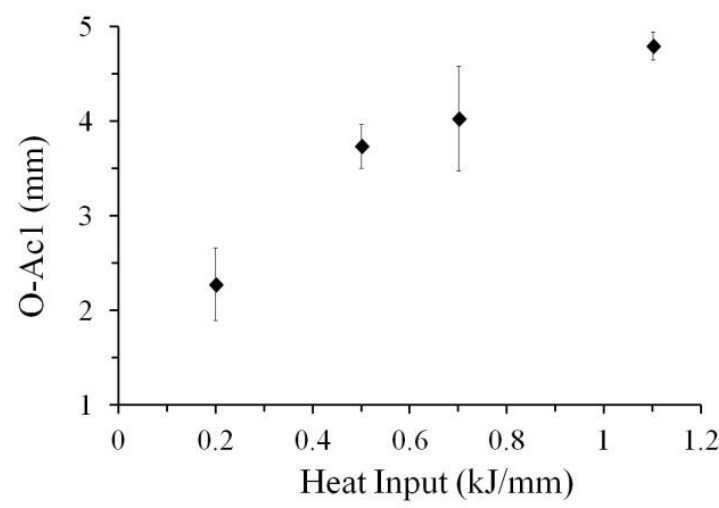

Fig. 6: Average Length of O-Ac1 as a Function of Heat Input.

\subsection{Microstructural analysis}

Weld metal W1 had highest hardness among all weldments with AWS ER80S-G. This could be attributed to its very low heat input (highest cooling rate), which in this case predominately promoted bainite formation, as can be seen in Figure 7(a). The other weldments, with higher heat inputs (lower cooling rates), have shown about 50 HV0.5 less than W1. This phenomenon was due to higher proportions of low hardness microconstituents, like acicular ferrite and grain boundary ferrite, as is shown in Figure 7(b).

(A)

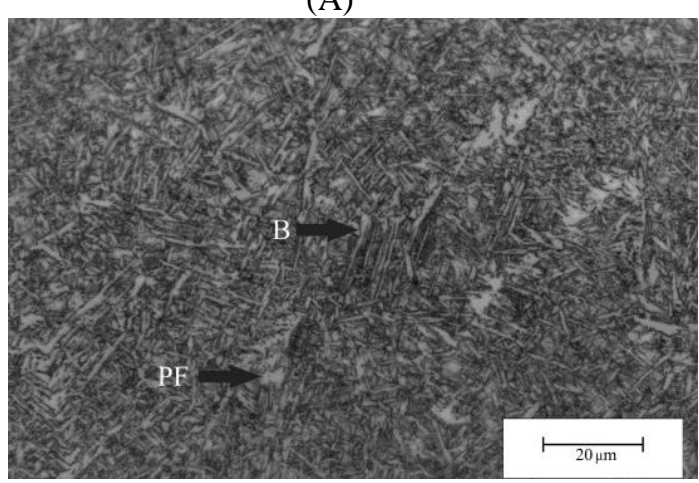

(B)

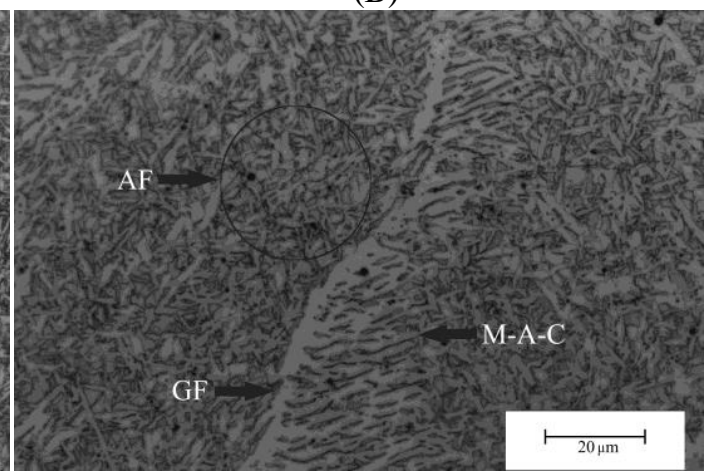

Fig. 7: Micrographs of WM: (A) W1 (0.2 kJ/mm); (B) W4 (1.1 kJ/mm). B: Bainite; PF: Polygonal Ferrite; AF: Acicular Ferrite; GF: Grain Boundary Ferrite; M-A-C: Ferrite with Martensite/Austenite/Carbides.

In the more distant regions of HAZ from the fusion boundary, the islands of martensite were partially dissolved to carbides and ferrite through tempering action, while the ferritic matrix remained practically unaffected [7]. This phenomenon is very noticeable on comparing the unaffected base metal in Figure 1(a), with the partially tempered base metal in Figure 8(a). As can be seen in the hardness profile of Figure 3, a gradient of hardness appears in this region, 
beginning right after the unaffected base metal and ending in a minimum value right before the subcritical region. This gradual decrease of hardness may be explained by associating temperature gradients developed in welding with the fact that tempering is a function of time and temperature [16]. In other words, increasing the tempering peak temperature (i.e. closer to weld metal) results in more pronounced drop of local haredness.

(A)

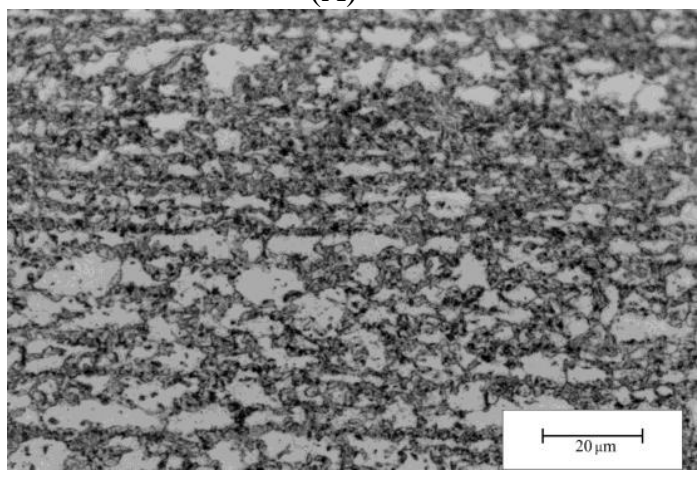

(C)
(B)

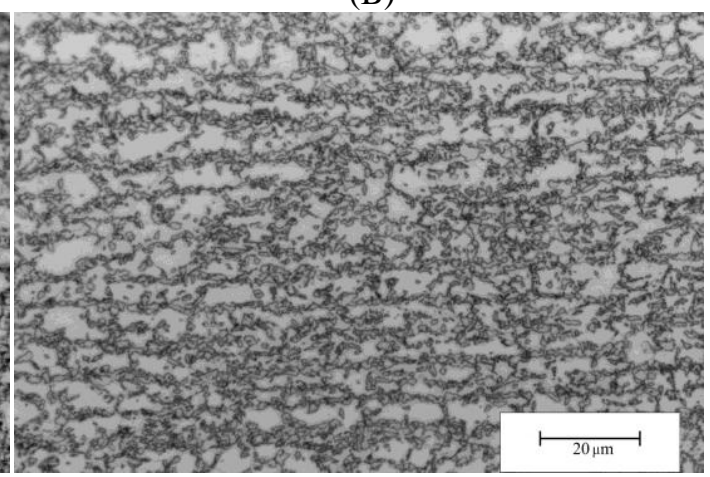

(D)

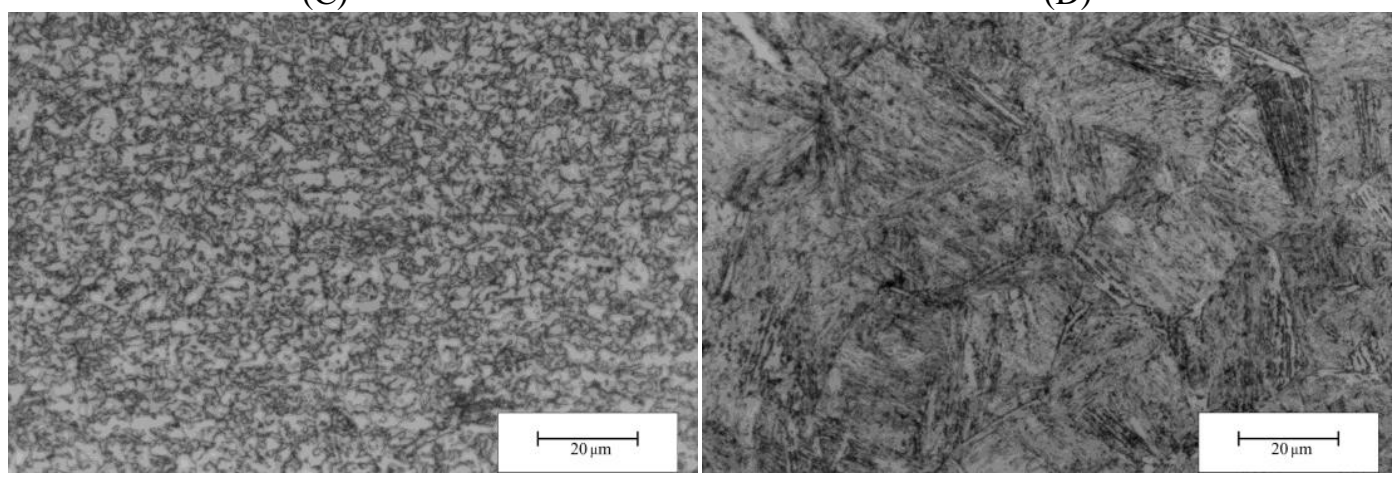

Fig. 8: Micrographs of HAZ: (A) Tempered Base Metal; (B) Subcritical Region; (C) Intercritical Region and (D) Grain Coarsening Region.

The phenomenon that occurred in the tempered base metal region repeats in the subcritical region, but is still necessary to describe it, due to its greater severity of temper. As stated before, the minimum values of hardness in the HAZ were found in this region for all experiments, without exception. According to the study of Biro et al. [8] on the HAZ of DP 600 and DP 780 steels, the end of the subcritical region coincides with the Ac1 isotherm boundary; thus the peak temperatures reached in this region were slightly lower than $\mathrm{AC} 1$. This region is also known as "region of softening", because it contains the highest decrease in HAZ hardness. Figure 8(b) shows the microstructure of this region, and it can be seen that martensite content is considerably less than unaltered base metal. It also can be observed that both ferrite and martensite apparently suffered recrystallization, since grain orientation is less pronounced.

The degree of softening due to welding DP steel was first presented in the work of Xia et al. [5], by calculating the decrease of hardness from the base metal to the lowest hardness value found in the HAZ, i.e. in the subcritical region. Figure 9 shows this degree of softening as function of heat input, for weldments of both filler metals. Degree of softening was calculated through equation (2), where HVBM is the average microhardness of base metal (325 HV0.5) and HVHAZmin is the minimum microhardness measured in HAZ. It can be seen that both curves resemble the "s" shape found in the work of Xia et al. [5], where DP 450, DP 600 and DP 980 steels were welded. It can be seen that for the welding conditions of the present study, a decrease of hardness in the HAZ of at least $22 \%$ is inherent to welding. The degree of softening increases as the heat input is increased, until it reaches a limit, staying around $30 \%$.

Softening $(\%)=(1-(($ HVMB - HVHAZmin $) / H V M B)) \times 100$

Right beside the subcritical region is the intercritical region, with peak temperatures reaching values between AC1 and AC3. As can be seen in Figure 8 (c), the microstructure is biphasic, being composed of ferrite and martensite, resembling the base metal, but with smaller grain size. This trend seems reasonable, given that in most cases the final microstructure of DP steels is obtained by a heat treatment called "intercritical annealing" [2], in which the steel is heated to intercritical temperatures, soaked and then cooled down. Being in the intercritical field, the refinement may have been caused by austenite recrystallization 17 and the presence of grain refining elements found in this steel. It can be also seen that the grains of this region seem to be less oriented than the ones of base metal.

As can be seen in Figure 8(d), the grain coarsening region has hard microconstituents such as bainite and martensite (probably lath type, due to the low material percentage of carbon). Since it is immediately beside the melted zone, the microstructure of the grain coarsening region completely transformed to austenite during heating, i.e., peak temperatures were above $\mathrm{AC} 3$ and below the melting temperature. Apparently the temperatures that were reached 
hindered the action of grain refining elements, and also worked to increase the austenitic grain size considerably. The combination of coarse austenite grain size [4] with the DP hardenability favored the formation of very hard microconstituents.

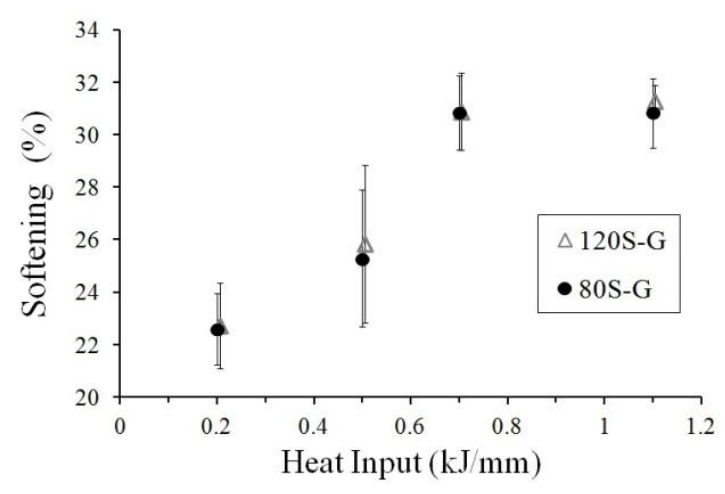

Fig. 9: HAZ Softening of the DP Steel Joints as a Function of Both Heat Input (kJ/mm) and Weld Metal Cross Section Area $\left(\mathrm{mm}^{2}\right)$.

\subsection{Uniaxial tensile testing}

All tensile tests fractured at the HAZ. Figures 10(a, b) show fractured specimen macrographs from weld metal face, both welded with $0.2 \mathrm{~kJ} / \mathrm{mm}$, but one with AWS ER80S-G as filler metal (a) and other with AWS ER120S-G (b). So, it is clear that the filler metals used were of little relevance to the final yield and tensile strength of the joints, since they were governed by microstructural changes in HAZ. The corresponding HAZ region where fractures occurred was in the vicinity of the subcritical region, where martensite was severely tempered. Similar results were found in the study of Panda et al. [6] who experimented and simulated the tensile behavior of a laser welded DP 980.

(A)

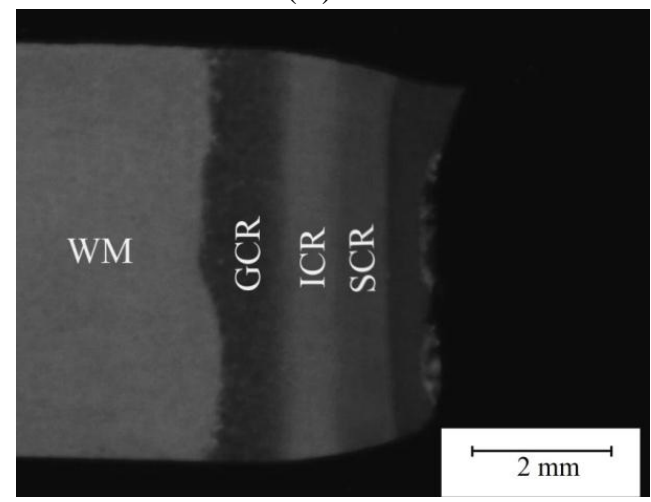

(B)

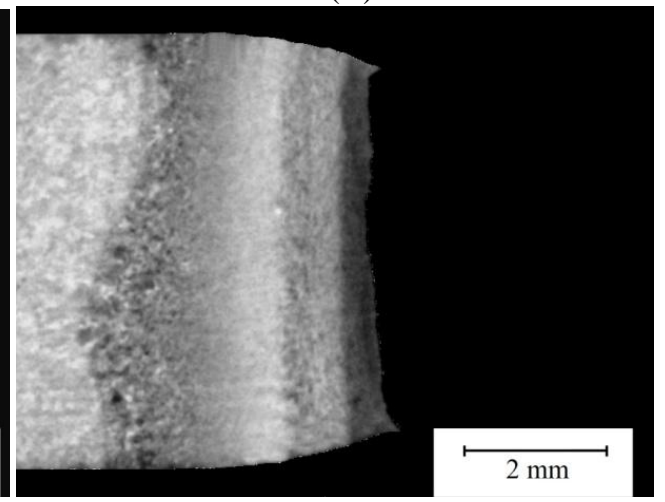

Fig. 10: Fractured Specimen Macrographs from Weld Metal Face of Joints Welded with (A) AWS ER80S-G and (B) AWS ER120S-G. Both Welded with Heat Input of $0.2 \mathrm{~kJ} / \mathrm{mm}$.

Figure 11 shows the results of yield and ultimate tensile strength as function of heat input for weldments made only with AWS ER80S-G filler metal, since weldments made with AWS ER120S-G were exploratory and they fractured at the HAZ. A minimum drop of around $23 \%$ in average tensile strength and around $18 \%$ in average yield strength compared to base metal, when welded with heat input of $0.2 \mathrm{~kJ} / \mathrm{mm}$ was observed.

It also can be seen in the previous figure that the drop of average strength (both tensile and yield) continues to increase with heat input; however it becomes less pronounced with higher heat inputs, staying around 30\% for tensile strength and $35 \%$ for yield strength. This behavior seems to follow that presented on HAZ softening, where the strength of joints did not decrease much after the degree of softening plateau was reached.

Elongation during tests was also measured (considering both filler metals) and is shown in Figure 12. It was noticed that average elongation tends to increase with increasing heat inputs, for both filler metals; however, for a same heat input, weldments with AWS ER80S-G always showed higher values than AWS ER120S-G. 


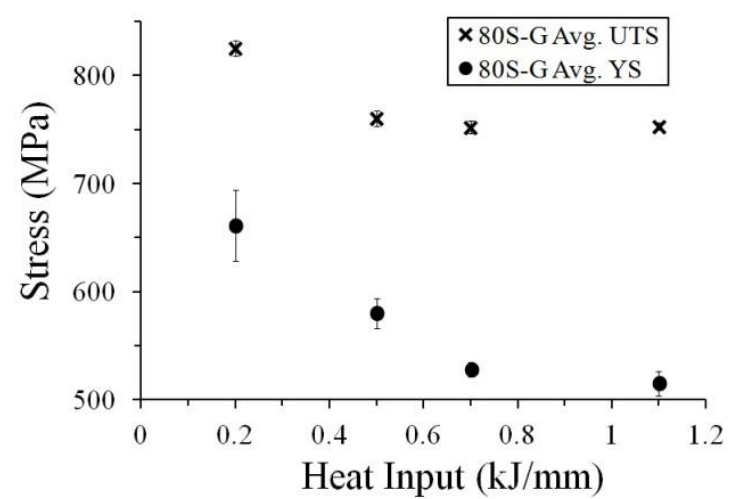

Fig. 11: Average Results of Ultimate Tensile Strength (UTS) and Yield Strength (YS) for Welded Joints with AWS ER80S-G as a Function of Heat Input.

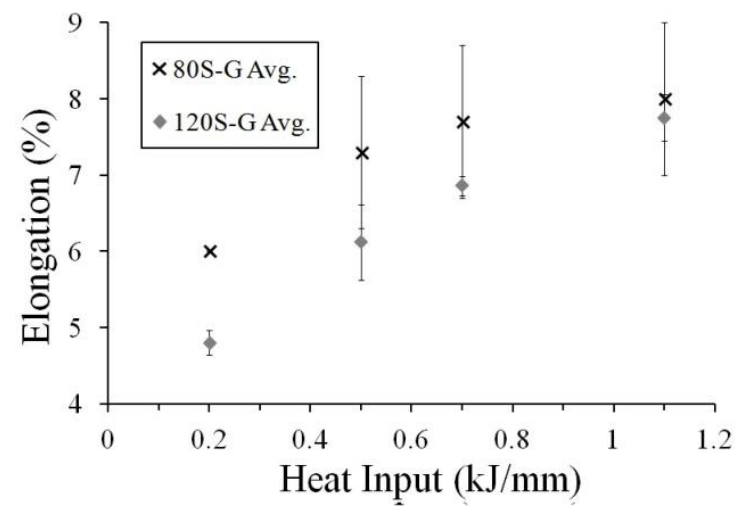

Fig. 12: Average Elongation as a Function of Heat Input, For Weldments with Both Filler Metals.

Part of the elongation was due to weld metals, but for the HAZ one possible explanation for this may be linked to the formation of new ferrite, as the product of martensite tempering in the HAZ. With the heat input increment, higher amounts of ferrite would be produced by tempering, justifying the gradual increase in ductility.

\section{Conclusions}

It was shown that GMAW of the DP 1000 steel used in this study is viable. Microstructural changes in HAZ reduced base metal ultimate tensile and yield strength; however, when heat input corresponded to $\Delta \mathrm{t} 8 / 5$ of $4.5 \mathrm{~s}$ (in this case 0.2 $\mathrm{kJ} / \mathrm{mm}$ ), this phenomenon was minimized. Perhaps, other values between 0.2 and less than $0.5 \mathrm{~kJ} / \mathrm{mm}$ have the same effect.

In all uniaxial tensile tests, in all conditions, fractures of the specimens always occurred at the same HAZ location, i. e., near subcritical region, where hardness values were very low and decomposition of martensite was quite severe. Coincidentally, in every experiment, weld metal minimum hardness was always greater than the minimum value found in the HAZ.

As heat input was increased, elongation also increased almost in a linear fashion. This could be related to the increase of new ferrite as a result of martensite tempering in HAZ.

Considering the welding conditions used in this study, ultimate tensile and yield strength of square butt welded joints of this material cannot be improved if welded with filler metals of higher strength than AWS ER80S-G (an undermatching wire), since fracture always occurred at the HAZ.

\section{Acknowledgments}

To Capes (Brazil) for granting the master's scholarship to one of the authors (ICLR); to LAMEF, where the tensile testing and chemical analysis were performed; and SSAB for providing the DP 1000 sheets.

\section{References}

[1] Steel Market Development Institute, AHSS 101: The Evolving Use of Advanced High-Strength Steels for Automotive Applications, 2011.

[2] R. Kuziak, R. Kawalla, S. Waengler, Advanced High Strength Steels for Automotive Industry, Achieves of civil and mechanical engineering, 8 (2), 2008, 103-117. 
[3] M. Askoy, A. Esin, Improving the Mechanical Properties of Structural Carbon Steel by Dual-Phase Heat Treatment. J. Mater. Eng., 10 (4), 1988, 281-287. http://dx.doi.org/10.1007/BF02834157.

[4] S. Kou, Welding Metallurgy, 2nd ed., John Wiley \& Sons, 2003, 393-405.

[5] M. Xia, E. Biro, Z. Tian, N. Zhou, Effects of Heat Input and Martensite on HAZ Softening in Laser Welding of Dual Phase Steels, ISIJ International, 48 (6), 2008, 809-814. http://dx.doi.org/10.2355/isijinternational.48.809.

[6] S. Panda, N. Sreenivasan, M. Kuntz, Y. Zhou, Numerical Simulations and Experimental Results of Tensile Test Behavior of Laser Butt Welded DP980 Steels, Journal of Engineering and Materials Technology, 130 (4), 2008, 041003-1 - 041003-9

[7] V.H Hernandez, S. Nayak, Y. Zhou, Tempering of Martensite in Dual-Phase and Its Effects on Softening Behavior, Metallurgical and Materials Transactions A, 42A (Oct.), 2011, 3115-3129.

[8] E. Biro, J. McDermid, J. Embury, Y. Zhou, Softening Kinetics in Subcrtitical Heat-Affected Zone of Dual-Phase Steel Welds, Metallurgical and Materials Transactions A, 41 (Sept.), 2010, 2348-2356.

[9] Y. Granbom, Structure and mechanical properties of dual phase steels - An experimental and theorical analysis. Thesis (Doctoral) - Royal Institute of Technology, School of Industrial Engineering and Management, Material Science Engineering, Division of Mechanical Metallurgy, Stockholm, Sweden, 2010.

[10] M. Calcagnotto, D. Ponge, D. Raabe, On the Effect of Manganese on Grain Size Stability and Hardenability of Ultrafine-Grained Ferrite/Martensite Dual-Phase Steels, Metallurgical and Materials Transactions A 43A (Jan.), 2012, 37-46.

[11] ASTM Standard E562-11, Standard Test Method for Determining Volume Fraction by Systematic Manual Point Count. Oct., ASTM International, West Conshohocken, PA, 2011.

[12] ASTM Standard E384-11, Standard Test Method for Knoop and Vickers Hardness of Materials. Aug., ASTM International, West Conshohocken, PA, 2011.

[13] ASTM Standard E8/E8M-13a, Standard Test Method for Determining Volume Fraction by Systematic Manual Point Count. Aug., ASTM International, West Conshohocken, PA, 2013.

[14] J. Trzaska, L.A. Dobrzánski, L.A., Modelling of CCT diagrams for engineering and constructional steels, Journal of Material Processing Technology, 192-193 (Oct.), 2007, 504-510. http://dx.doi.org/10.1016/j.jmatprotec.2007.04.099.

[15] I.G Machado, Heat Conduction in Welding: Fundaments \& Applications (in portuguese), 1a ed., Imprensa Livre Editora Ltda, $200,28-31$.

[16] A. Sayed, S. Kheirandish, Effect of Tempering Temperature on the Microstructure and Mechanical Properties of Dual Phase Steels, Materials Science and Engineering A 532 (Jan.), 2012, 21-25. http://dx.doi.org/10.1016/j.msea.2011.10.056.

[17] H. Svoboda, H. Lorusso, A. Burgue-o, Soldadura de Aceros Dual Phase en Chapa Fina: GMAW, PAW y RSW, Soldagem \& Inspeção, 16 (2), 2011, 165-176. http://dx.doi.org/10.1590/S0104-92242011000200009. 